\title{
O FENÔMENO DA BRISA E SUA RELAÇÃO COM A CHUVA SOBRE FORTALEZA-CE
}

\author{
RAUL FRITZ BECHTEL TEIXEIRA \\ Fundação Cearense de Meteorologia e Recursos Hídricos, Departamento de \\ Meteorologia e Oceanografia - Fortaleza - Ceará. \\ fritz@funceme.br
}

Recebido Fevereiro 2007 - Aceito Janeiro 2008

\begin{abstract}
RESUMO
A análise da freqüência horária de chuva sobre a cidade de Fortaleza, situada na costa do Ceará e no norte do Nordeste do Brasil, reafirmou a já conhecida maior incidência de precipitação no período noturno do dia, principalmente durante a madrugada, até o início da manhã, ao longo do ano. Essa análise também mostrou uma redução das chuvas no local, no período vespertino do dia. A observação de imagens fornecidas por satélites meteorológicos, registros de chuva e campos de ventos a partir de modelos numéricos de tempo sugerem neste estudo, que a passagem da porção ocidental da frente de brisa terrestre (sistema freqüentemente formado entre o leste do Ceará e o norte do Rio Grande do Norte), pela área de Fortaleza (e vizinhanças) facilita, a partir da sua convergência com os ventos alísios de sudeste, a ocorrência de chuvas em geral rápidas e pouco intensas notadamente entre a madrugada e o início da manhã. Além disso, a convergência dessa brisa com sistemas meteorológicos de grande escala também deve contribuir para a freqüência elevada de precipitação no período mencionado. Neste caso, em geral as chuvas são mais intensas. Por outro lado, a brisa marítima coopera para a menor incidência de chuva em Fortaleza (sob área de supressão de cumulus), no período da tarde.

Palavras-chave: meteorologia de mesoescala, brisa, chuva, Ceará.
\end{abstract}

\begin{abstract}
THE BREEZE PHENOMENOM AND ITS RELATIONSHIP WITH THE RAIN OVER FORTALEZA-CE

The analysis of the hourly rain frequency over Fortaleza City, located at Ceará State coast and in the north-northeastern Brazil, confirmed the well known higher rain incidence in the nocturnal period of the day, mainly during dawn until the early morning, throughout the year. The rain frequency analysis also showed a local reduction of the rains during the afternoon. The observation of meteorological satellite images, rainfall data and wind fields produced by numerical weather models have suggested, in this study, that the transit through the Fortaleza area (including its surroundings) of the western portion of the land-breeze front (system originated frequently between the eastern Ceara coast and the northern Rio Grande do Norte), may facilitate, through the convergence with the southeasterly winds, the occurrence of short duration, light rains mainly near dawn until the early morning. Moreover, the convergence of those breezes with large scale systems may also contribute to the high frequency of rains in the mentioned period. In this case, heavy precipitation can be generated. Otherwise, the sea-breeze observed in Ceara seems to cooperate to the lesser observed rain incidence in Fortaleza (under an area of cumulus suppression) during the afternoon period.
\end{abstract}

Keywords: meso-scale meteorology, land-see breeze, rain, Ceara. 


\section{INTRODUÇÃO}

O fenômeno de circulação da brisa tipifica um sistema atmosférico de meso-escala (Rotunno et al., 1992), e de regiões costeiras (Ahrens, 2000). Identificadas pelos antigos gregos desde cerca de 350 a.C. e representando um sistema de vento local (Vianello e Alves, 1991), ou um regime específico de vento, de escala diurna, decorrente das diferenças térmicas entre as superfícies terrestres e marítimas que levam a diferenças de pressão do ar em baixos níveis, sobre essas superfícies, as brisas são de dois tipos: de mar e de terra. Elas são induzidas por heterogeneidades espaciais do fluxo de calor superficial na camada limite planetária (Rotunno et al., 1992).

As brisas assumem um papel de certo destaque, em termos de regularidade e intensidade de ocorrência, em determinadas áreas tropicais tais como em grande parte do litoral do Nordeste brasileiro (doravante chamado apenas de Nordeste). A brisa marítima, por exemplo, pode ocorrer em 3 de cada 4 dias ao longo das costas tropicais (Heidorn, 1998). As brisas são mais pronunciadas nos trópicos do que nas latitudes médias, principalmente em virtude da aceleração de Coriolis ser mais fraca nas áreas tropicais. Em latitudes maiores, essa aceleração desvia o vento, limitando, dessa forma, o alcance das brisas. Assim, nos trópicos os processos de meso-escala e de escala diurna, tais como as brisas, são particularmente importantes (DeCaria, 2005).

Até cerca de $30^{\circ}$ de latitude em ambos os hemisférios do nosso planeta, ocorre forte ciclo diurno do vento próximo à superfície, no oceano Atlântico e ao longo das regiões costeiras localizadas nesse oceano. Isso inclui o Nordeste, em que os ventos oceânicos mais intensos, junto à costa, são encontrados no norte dessa região (Gille et al., 2005). Considerando a variação diurna da precipitação no Nordeste, grande parte da área costeira (principalmente a parte leste) experimenta um máximo de precipitação no período noturno até o início da manhã (entre $21 \mathrm{~h}$ e $9 \mathrm{~h}$ local) devido à convergência entre o fluxo médio de ar próximo à superfície e procedente do oceano, e o fluxo superficial do continente para o mar devido à brisa terrestre. Nas áreas entre $150-300 \mathrm{~km}$ para dentro do continente, observa-se porém, um máximo da precipitação no período entre $15 \mathrm{~h}$ e 21 $\mathrm{h}$ local, associado com o desenvolvimento e avanço da brisa marítima (Kousky, 1980).

Os trechos da costa norte do Nordeste apresentando formato aproximadamente côncavo e com centros de curvatura situados em torno de $37^{\circ}$ (noroeste do Rio Grande do Norte) e $41^{\circ}$ de longitude Oeste $\left(41,5^{\circ}\right.$ corresponde ao meio do litoral do Piauí) não registram máximos de precipitação no horário 21 h -9 h local. Nessas áreas, o fluxo médio de sudeste, ao longo do ano e em baixos níveis, do continente para o oceano, tem direção pouco inclinada em relação à costa. Ao se acoplar com a brisa terrestre, ele produz uma zona de convergência (visível como um "arco" de nuvens em imagem de satélite) sobre a área oceânica próxima à costa (Kousky, 1980).

Por outro lado, sobre a área litorânea de Fortaleza, localizada entre as duas áreas côncavas citadas, a maior parte dos eventos de chuva acontece entre 21 h e 9 h local (Kousky, 1980).

Em vista disso, busca-se neste trabalho avaliar a relação entre o máximo de ocorrência de precipitação em Fortaleza (extensível a alguns municípios cearenses nas vizinhanças imediatas da cidade) e a brisa terrestre (e sua interação com o escoamento local).

Outrossim, foi observada uma redução da incidência de chuva na área englobando Fortaleza e nos horários 9 - 15 h e 15 - 21 h local. Foi estudado o período de 1961 a 1970, tanto para se encontrar esse mínimo quanto para o máximo anteriormente mencionado (Kousky, 1980). Assim este trabalho visa também, trazer alguns esclarecimentos adicionais sobre essa mínima incidência de precipitação, que envolve a brisa marítima (e sua interação com o escoamento local).

A brisa terrestre ainda é menos compreendida do que a brisa marítima (Rotunno et al., 1992). Estudos sobre chuvas continentais decorrentes de influências de brisas marítimas, lacustres e de vale-montanhas são abundantes no meio científico, mas trabalhos mostrando influências de brisas terrestres nas chuvas sobre áreas continentais são mais escassos mesmo porque se espera, geralmente, que brisas terrestres favoreçam precipitações sobre o oceano e não sobre o continente. Dessa forma, o principal enfoque deste estudo se refere à maior compreensão sobre o mecanismo da brisa terrestre que favorece a grande incidência de chuva entre a noite (principalmente a madrugada) e o início da manhã em Fortaleza (e seus arredores próximos). As chuvas nesse período, quando se apresentam intensas, trazem diversos transtornos à população da capital, tais como o alagamento de áreas críticas, notadamente na periferia, e a dificuldade de deslocamento para o trabalho, escola, etc., no começo da manhã, devido à inundação de vias públicas em alguns pontos da cidade.

Para o desenvolvimento deste estudo, a utilização de informações fornecidas por satélites meteorológicos, inclusive seqüências animadas de imagens, foram fundamentais para a observação de linhas de nebulosidade associadas às brisas propagando-se no Ceará, em áreas oceânicas junto ao litoral desse estado, do Piauí, do nordeste do Maranhão e do norte do Rio Grande do Norte. Campos de ventos em baixos níveis resultantes de análises e previsões de modelos numéricos de tempo, globais e regionais também auxiliaram o entendimento dos processos envolvidos ao mostrarem os padrões de escoamentos médios locais com os quais as brisas interagem. No caso de Fortaleza e arredores, foram usados ainda, alguns 
registros de precipitação a partir de plataformas automáticas de coleta de dados meteorológicos em horários próximos aos horários das imagens de satélite para comprovar os mecanismos meteorológicos em atuação no local.

Portanto, o presente trabalho busca um melhor entendimento a respeito da influência da brisa terrestre sobre as chuvas em Fortaleza e vizinhanças no período da noite (principalmente na madrugada) para o início da manhã, e a influência da brisa marítima reduzindo as chuvas na área, no período da tarde.

\section{MATERIAL E MÉTODOS}

Inicialmente, foram estudados 14 anos (período de 1974 a 1987) de registros horários de chuva obtidos pela estação meteorológica convencional da FUNCEME, na cidade de Fortaleza, a fim de complementar o estudo sobre o ciclo diurno de precipitação investigado em trabalho pioneiro envolvendo o Nordeste (incluindo a região englobando Fortaleza), e alguns estados vizinhos do Norte do Brasil (Kousky, 1980). Esse período foi escolhido porque a referida estação começou a funcionar em 1974, com medições pluviométricas contínuas ao longo do dia prosseguindo até 1987. Após esse ano, têm-se somente registros de precipitações acumuladas em 24 horas. O período entre 1974 e 1987, apesar de compreender apenas 14 anos de extensão, pode ser considerado representativo da climatologia local já que ele abrange anos tipicamente muito chuvosos (como 1974 e 1985), normais (como 1978) e muito secos (1979 e 1983) (Teixeira, 2002; Xavier, 2001).

$\mathrm{Na}$ análise dos dados, foi considerada apenas a ocorrência de precipitação não se levando em conta a intensidade das chuvas. Para cada horário do dia, de cada mês e de cada ano, contabilizou-se o total de dias com ocorrência de chuva. Tabelas de freqüência de chuva por hora, para cada mês e para o período, foram construídas com os dados disponíveis. A partir delas foram elaborados histogramas do número de dias com chuva segundo o horário e, usando-se esses últimos, foram desenhados polígonos de freqüência representando o número de dias com chuva segundo a hora, para cada mês e para o período considerado. Isso permitiu se verificar os horários de maior e menor freqüência de precipitação, em cada mês e no período abordado. Um polígono de freqüência foi, então, gerado para o primeiro semestre do ano, onde se concentra a maior parte da precipitação (inclusive maior volume de chuva) sobre o norte do Nordeste principalmente nos meses de março e abril (Kousky, 1979; Hastenrath e Heller, 1977; Strang, 1972), considerado, portanto, o semestre "chuvoso", e outro foi elaborado para o segundo semestre (considerado muito pouco chuvoso, ou "seco").

Além disso, foram usadas informações de satélites, dentre as quais inúmeras imagens diárias do Ceará e dos estados vizinhos Maranhão, Piauí e Rio Grande do Norte, fornecidas pelos satélites meteorológicos de órbita polar da série NOAA e geradas na FUNCEME, do ano de 2004 e 2005, para uma rápida identificação visual e subjetiva dos sistemas meteorológicos atuantes na região e, em especial, para a observação da nebulosidade relacionada às linhas de convergência que aparecem próximo ao litoral da região em consideração, principalmente aquelas aparentemente vinculadas, de forma típica, às brisas (ou frentes de brisa), que tendem a ter padrões semelhantes e repetitivos (diários), pois a ocorrência de brisa tende a ser regular a cada dia e no mesmo horário em países tropicais (Simpson, 1994). Essa nebulosidade se manifesta na forma de linhas ou arcos de nuvens nas proximidades das frentes de brisa no período da tarde para o início da noite, no caso da brisa marítima, avançando para dentro do continente, e da madrugada para a manhã, em relação à brisa terrestre, avançando para o oceano. Imagens, no visível e no infravermelho, de resolução de $1 \mathrm{~km}$, a partir dos satélites NOAA, mostraram-se particularmente interessantes para a observação dessas linhas de nuvens. Recentemente, a FUNCEME passou a gerar imagens, também no visível e em outras faixas de comprimentos de onda, a cada 15 minutos, a partir de satélite geoestacionário MSG (Meteosat Second Generation). Essa elevada freqüência de tempo permitiu se observar melhor a formação e evolução das linhas de nuvens associadas às brisas, em alguns casos relativos aos anos de 2006 e 2007. Algumas das imagens meteorológicas NOAA e MSG utilizadas, foram então, selecionadas e inseridas no texto para ilustrar os fenômenos observados.

Alguns campos de ventos de modelos numéricos, em baixos níveis (até $850 \mathrm{mb}$ ), da região sob estudo e da época de cada imagem utilizada, obtidos da página da Internet do Centro de Previsão de Tempo e Estudos Climáticos (CPTEC)/ Instituto Nacional de Pesquisas Espaciais (INPE), foram usados para se observar o fluxo médio na região de atuação das brisas já que estas interagem com esse fluxo (Kousky, 1980).

Procurou-se ainda, verificar registros de chuva em Fortaleza e vizinhanças, coincidentes com a nebulosidade, em forma de arco, observada nas imagens de satélites e relacionada às brisas terrestres.

Em suma, buscou-se observar alguns aspectos da dinâmica de atuação das brisas na região considerada. Atenção especial foi dada à brisa terrestre na sua relação com precipitações em Fortaleza e arredores no período da madrugada para o início da manhã.

\section{RESULTADOS E DISCUSSÃO}

A figura 1 mostra o polígono de freqüência, ou a freqüência de chuva por hora, no período de 1974 a 1987, para Fortaleza, para cada mês do primeiro semestre (chuvoso). 
Observa-se a partir da figura, que os meses de março e abril apresentam o maior número de dias chuvosos, seguidos dos meses de maio, junho e fevereiro e, por fim janeiro. Mas um grande destaque da figura se refere à concentração das chuvas no período noturno (principalmente na madrugada) até o início da manhã para todos os meses considerados. O período da tarde é o que apresenta a menor freqüência também em todos os meses do primeiro semestre. Percebe-se ainda, uma gradual elevação do número de eventos de chuva no início da noite.

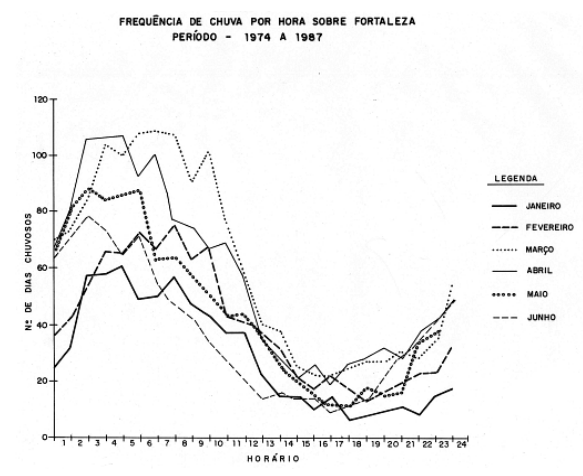

Figura 1- Freqüência de chuva por hora para os meses de janeiro a junho, para o período de 1974 a 1987, e para a estação meteorológica de Fortaleza.

A figura 2, semelhantemente à figura anterior, mostra a freqüência de chuva por hora para o segundo semestre (muito pouco chuvoso, ou seco). Observa-se redução do número de eventos de chuva, quando comparado com o primeiro semestre. Nota-se ainda, como se verifica no primeiro semestre só que numa magnitude menor, que a maior parte das chuvas se concentra no período da madrugada para o início da manhã. No horário da tarde, observa-se uma sensível redução da ocorrência de precipitações.

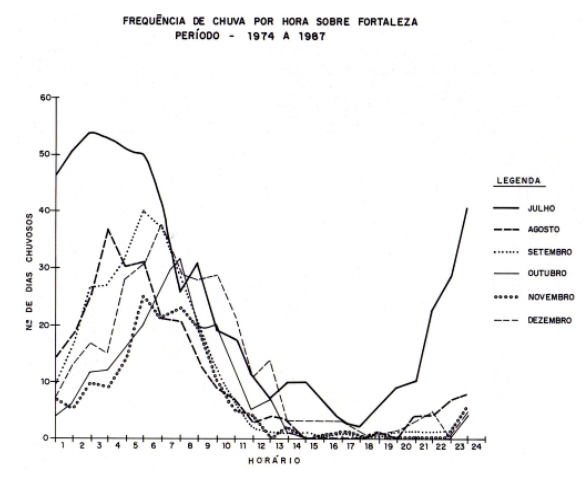

Figura 2 - Freqüência de chuva por hora para os meses de julho a dezembro, para o período de 1974 a 1987, e para a estação meteorológica de Fortaleza.
Resultados similares aos mostrados nas figuras $1 \mathrm{e}$ 2 foram relatados por Kousky (1980), para o período 1961 $-1970$.

A figura 3 exemplifica a atuação de brisa marítima no Ceará. Nebulosidade em forma de linha no período da tarde, aproximadamente paralela à costa e para dentro do continente identifica a brisa marítima. A diferença térmica entre a terra aquecida e o oceano mais frio aumenta ao longo do dia e a circulação da brisa se intensifica. A frente de brisa avança para dentro do continente (Simpson, 1994). À tarde, quando o contraste térmico entre a terra e o oceano é máximo, a brisa alcança sua maior intensidade (Ahrens, 2000). As nuvens próximas à frente podem então, se apresentar mais desenvolvidas verticalmente. Na figura, a primeira linha de nuvens (próximo à frente de brisa) a partir da costa, apresenta cumulus mais desenvolvidos, principalmente em direção ao final da tarde. Desde as nuvens até ao mar, encontra-se uma faixa de céu predominantemente claro correspondendo à área de supressão de cumulus até a região de subsidência da circulação (Rotunno et al., 1992). Normalmente, esse mecanismo dificulta a ocorrência de precipitação na costa, incluindo Fortaleza no período da tarde, como indicado nas curvas de freqüência de chuva por hora, se não estiver atuando algum outro mecanismo (de maior escala) mais importante e que se sobreponha à brisa.
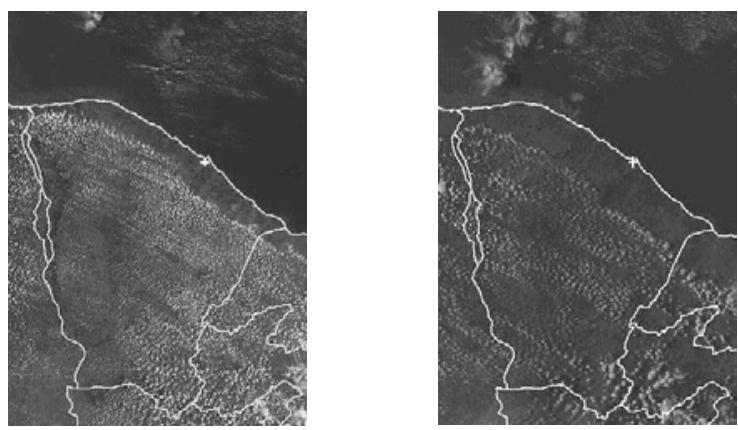

Figura 3 - Circulação de brisa marítima, à tarde sobre o Ceará. A faixa litorânea apresenta-se sem nuvens. Fortaleza é representada por uma pequena cruz. Imagens no canal visível dos satélites meteorológicos NOAA-16, 10/09/2004, 14 h local (à esquerda) e NOAA-12, mesmo dia, 16:17 h local (à direita).

As brisas não são fenômenos exclusivos de tempo claro. Elas afetam e interagem com vários tipos de nuvens (Rotunno et al., 1992). É comum se observar (Figura 4 - a e b, e mesmo na figura anterior) na intersecção (convergência) entre a frente da brisa marítima (dentro do continente) e a área de convecção (identificada por linhas de cumulus formando ruas de nuvens) entre rolos convectivos horizontais, um maior desenvolvimento vertical das nuvens, podendo aparecer cumulus bem desenvolvidos. Em alguns casos, isso pode favorecer a ocorrência de chuvas significativas nessa área (Teixeira, 2004; Dailey e Fovell, 1999). 


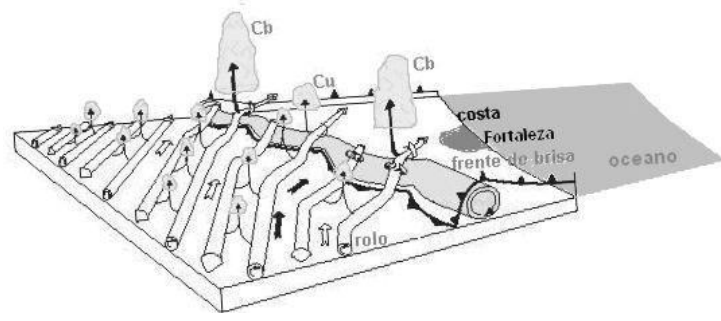

Figura 4 a) - Convergência entre a frente de brisa e rolos convectivos devidos ao escoamento superficial médio (no caso do Ceará correspondendo aos alísios de Sudeste) que forma um determinado ângulo com a circulação da brisa. A linha de nuvens mais desenvolvidas verticalmente, aparece numa certa distância da costa onde se localiza Fortaleza. Adaptado de Wilson et al.,1998 e Atkins et al., 1995.

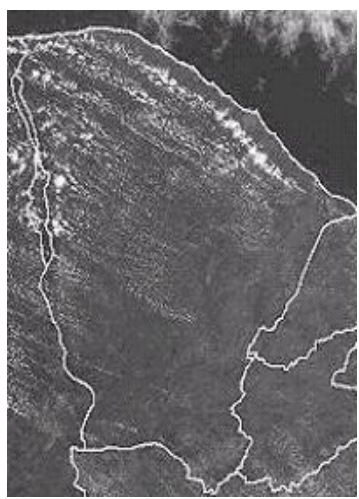

Figura 4 b) - Imagem, no visível, fornecida pelo NOAA-16 em 11/02/2004, $14 \mathrm{~h}$ local, mostrando linha de nuvens mais desenvolvidas próximas à costa do Ceará, devido ao mecanismo apresentado na figura 4-a.

No caso, ainda, da figura 4-b (correspondente à época do início da estação chuvosa principal local), os alísios de Sudeste chegavam praticamente paralelos à costa cearense como no caso da figura 3 (fora da estação chuvosa, no semestre seco). Entretanto, o mecanismo descrito anteriormente, pode ser intensificado dependendo do período do ano. Quando o escoamento médio de grande escala incide mais perpendicularmente à costa, a partir do oceano, a brisa marítima pode ser fortalecida (Kousky, 1980). Para a região de estudo, isso é mais freqüente no período da estação chuvosa principal no primeiro semestre.

A figura 5 mostra campo de vento à superfície medido pelo satélite QuikSCAT destacando a área de convergência da Zona de Convergência Intertropical - ZCIT nas proximidades do litoral do Ceará (principalmente a sua parte oeste), onde o escoamento aparece quase perpendicular à costa. Nesta figura, observa-se a influência desse escoamento sobre a brisa marítima (num dos meses mais chuvosos da estação chuvosa principal local) levando a um maior desenvolvimento das nuvens desse sistema, notadamente no oeste do estado, e proporcionando chuvas significativas na região.
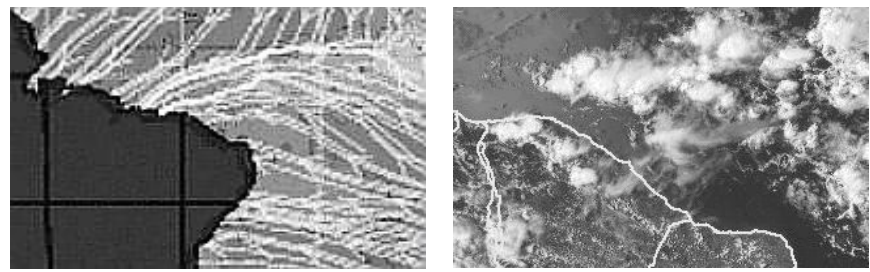

Figura 5 - Linhas de corrente à superfície mostrando o escoamento relacionado à ZCIT, medidas pelo satélite QuikSCAT, 22/03/2005, 9 $\mathrm{h}$ local (à esquerda). Imagem no canal visível, do NOAA-16, mesma data, $14 \mathrm{~h}$ local (à direita) mostrando intensificação da nebulosidade da brisa marítima devido ao escoamento quase perpendicular à costa.

Por outro lado, quando o continente começa a se resfriar para o final do dia, ocorre um momento em que o contraste térmico com o mar desaparece e a brisa marítima também. À noite, a diferença de pressão desaparece e tende a ser revertida dando origem à brisa terrestre (Simpson, 1994). Ocorre em geral, um período de calmaria nessa transição. Pela madrugada, a temperatura à superfície no litoral, já se encontra mais baixa do que a temperatura da superfície do mar; os ventos superficiais sopram do continente para o oceano, na brisa terrestre já formada. $\mathrm{Na}$ área oceânica forma-se convecção, aparecendo nuvens. Pela manhã, é possível observar uma linha de nuvens junto à frente de convergência da brisa terrestre, acompanhando a costa, mas sobre o oceano. A figura 6 exemplifica linhas de nuvens sobre o oceano associadas à brisa terrestre.
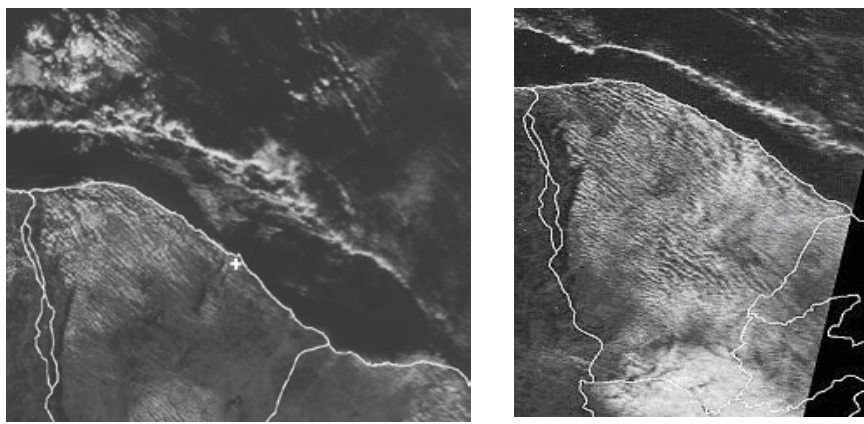

Figura 6 - Linhas de nuvens no oceano, associadas à brisa terrestre. Imagens, no visível, do NOAA-17, 11/08/2005, 10:26 h local (à esquerda), e 15/08/2005, 10:35 h local (à direita). A pequena cruz representa Fortaleza.

Em seguida na figura 7, tem-se uma interessante imagem de satélite em que aparecem os dois tipos de brisa atuando próximo à costa do Ceará. No oceano, a brisa terrestre deve estar em fase final de vida e dentro do continente a brisa marítima encontra-se em fase de expansão.

O fenômeno da brisa pode ser estudado considerando-se, basicamente, aspectos de circulação. No entanto, as brisas são 


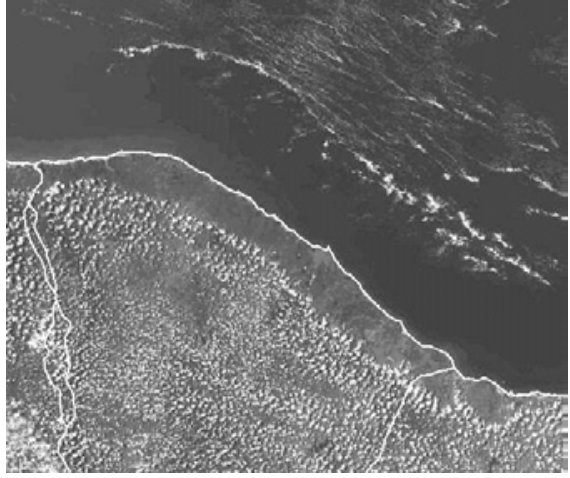

Figura 7 - Brisas atuando no Ceará. Imagem, no canal visível, do NOAA-16, 14:20 h, 24/08/2005.

controladas por uma variedade de fatores tais como a orientação do vento sinótico em relação à costa, a geometria (curvatura) da linha da costa, a complexidade do terreno, padrões de uso da terra e umidade do solo, etc (Baker et al., 2001; Rotunno et al, 1992; McPherson, 1970). Em relação à geometria da costa, o formato da costa entre o litoral leste do Ceará (a leste de Fortaleza) e o norte do Rio Grande do Norte é côncavo (com centro em torno de $37^{\circ}$ de longitude Oeste conforme mencionado anteriormente). Possivelmente devido a essa curvatura, a direção convergente, à superfície, dos fluxos de ar da célula de circulação da brisa em combinação com os ventos sinóticos (alísios), gera uma frente de brisa, no oceano, que dá origem em geral, a nuvens dispostas na forma de um grande arco com concavidade contrária à concavidade da costa. É importante destacar, conforme se observa na figura 8 , que a extremidade oeste da frente de brisa (que é uma área de convergência) pode, em certo momento, se posicionar sobre Fortaleza favorecendo a formação de nuvens e a ocorrência de chuva sobre a cidade na madrugada ou próximo do início da manhã e, em seguida, continuar seu deslocamento rumo ao oceano. No exemplo da figura, choveu em Fortaleza e no litoral do Pecém, situado a noroeste da capital, em horários correspondentes à nebulosidade associada à brisa, mostrada nas imagens, e conforme registros pluviométricos de plataformas de coleta de dados (PCDs), da FUNCEME. Nesta figura, vê-se também outra linha de nuvens associada à brisa terrestre e com formato de arco, devido à concavidade do litoral do nordeste do Maranhão, Piauí e do extremo noroeste do Ceará (concavidade com centro na longitude $41^{\circ}$ Oeste conforme mencionado anteriormente).

Assim, durante a madrugada, a área de convecção junto à frente de brisa terrestre pode estar localizada sobre Fortaleza ou próximo dela e a chuva pode vir a acontecer nesse período. Mesmo estando sobre o mar próximo à cidade, as nuvens formadas na área de convecção podem ser carreadas em direção à Fortaleza pela combinação resultante da circulação da brisa em altitude (níveis médios), no sentido do mar para a terra (direção nordeste, aproximadamente), com o escoamento de grande escala no local (predominantemente sudeste, da superfície até níveis médios).

A figura 9 ilustra novamente, o mecanismo da brisa terrestre atuando, pela madrugada, no litoral do Ceará e favorecendo a ocorrência de chuvas de pequena intensidade (próximas de $10 \mathrm{~mm}$ ) em Fortaleza e vizinhanças (como nos municípios de Aquiraz e Eusébio, por exemplo). A linha de nebulosidade associada à frente da brisa terrestre avança mar adentro (ver figura 6 , da direita, referente à mesma data, porém num horário posterior) após ter contatado a área de Fortaleza.

A circulação de brisa terrestre parece se acoplar, portanto, ao fluxo ou escoamento (úmido) médio (dependendo da direção e intensidade deste) próximo à costa, resultando em arcos de nuvens em deslocamento para o oceano cujo segmento extremo ocidental pode favorecer a precipitação na região de Fortaleza e arredores, entre a madrugada e o início da manhã. Também é bastante provável que com o eixo de convergência da ZCIT próximo à costa do Ceará (com o escoamento do oceano para o continente), no período chuvoso principal, a frente da brisa terrestre passando pela região de Fortaleza pode se acoplar a esse
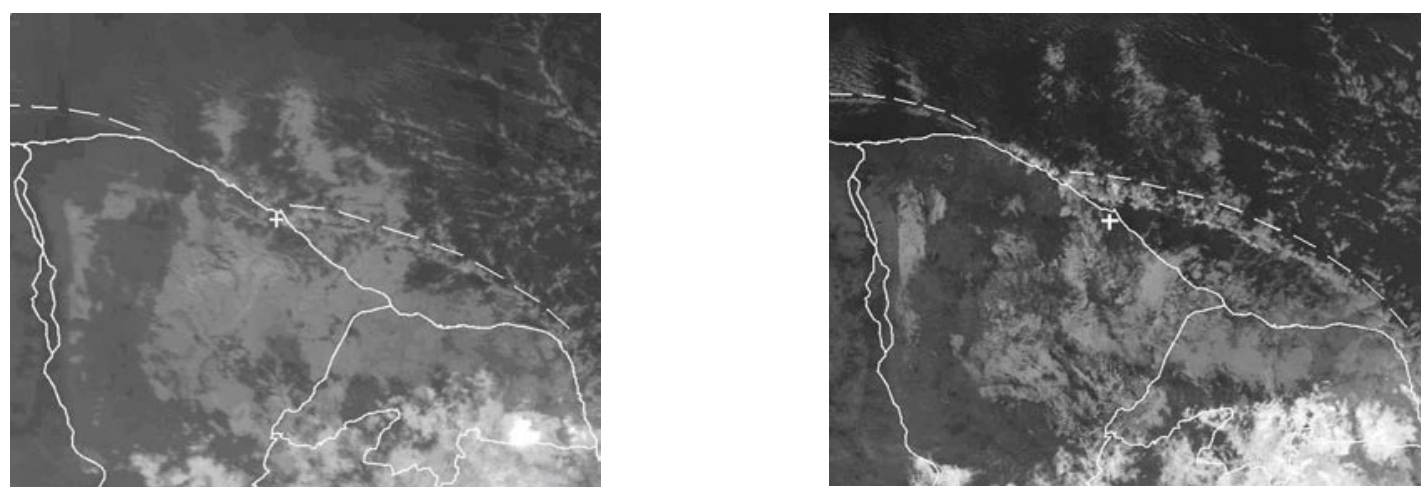

Figura 8 - Imagens, no infravermelho, mostrando a brisa terrestre (linha tracejada curva) que provocou chuvas rápidas, na madrugada, em Fortaleza (pequena cruz) e no litoral do Pecém, no Ceará. NOAA-12, 3:42 h local, 25/08/2005 (à esquerda) e NOAA-15, 5:33 h local, mesma data (à direita). 
sistema de grande escala aumentando a freqüência de chuvas no período da madrugada para o início da manhã na região. Com a participação da ZCIT, é evidente que as chuvas tendam a ser mais intensas do que aconteceria só com a atuação da brisa.
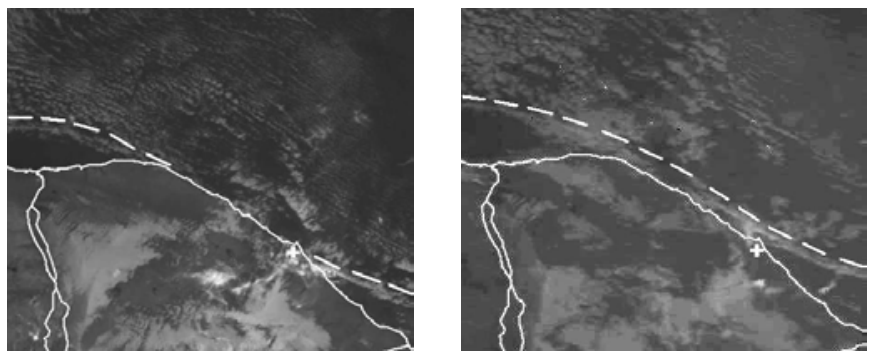

Figura 9 - Imagens, no infravermelho, da nebulosidade associada à frente de brisa terrestre (representada, aproximadamente, por linha tracejada), NOAA-12, 15/08/05, 4:30 h local (à esquerda) e NOAA15, mesmo dia, 6:10 h local (à direita). A pequena cruz representa Fortaleza.

Com respeito ainda à influência da geometria do litoral (Baker et al, 2001; Simpson et al, 1980; Pielke, 1974; McPherson, 1970), talvez a forma côncava possa produzir, na brisa terrestre, uma convergência em baixos níveis mais forte do que ocorreria se o litoral fosse aproximadamente retilíneo ou convexo. Isso poderia fortalecer o acoplamento da brisa terrestre com sistemas de grande escala tais como a ZCIT.

Assim, as precipitações ao longo do ano na capital cearense (e arredores), devido à influência unicamente das brisas de terra, tendem a ser em geral, rápidas e pouco intensas. $\mathrm{Na}$ figura 10 vê-se imagem de satélite (retirada de uma seqüência de imagens) mostrando a brisa em atuação no litoral do Ceará e provocando chuvas leves em Fortaleza e proximidades coincidentes com os horários das imagens, durante a estação seca. Também aparece campo de vento em baixo nível, a partir de modelo numérico regional de tempo, mostrando escoamento típico de sudeste junto ao litoral do Ceará.
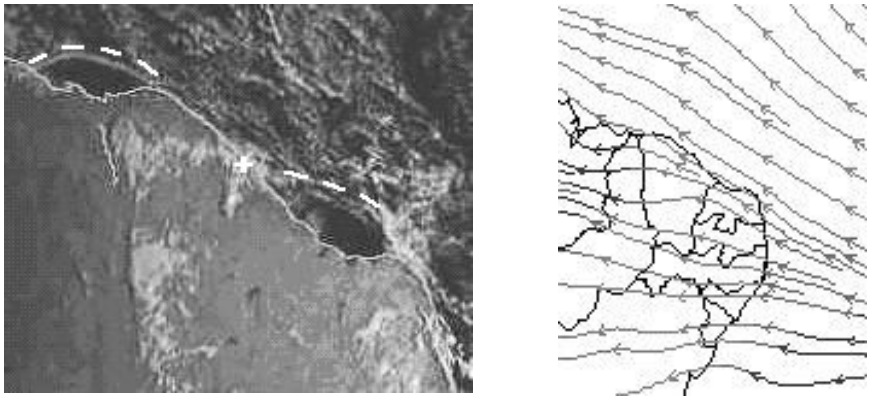

Figura 10 - Imagem MSG-1, no infravermelho, 06/10/2006, $6 \mathrm{~h}$ local, mostrando linhas de nuvens (em tracejado) associadas ao fenômeno da brisa terrestre. As imagens posteriores (que não aparecem aqui) mostravam a evolução das linhas se afastando da costa. Fortaleza é representada pela cruz. À direita, análise de vento a $850 \mathrm{hPa}$, do dia 5 às 21:00 h, a partir do modelo Eta (CPTEC/INPE). As previsões do modelo para as horas seguintes indicavam mesma direção de vento.
A figura 11 mostra uma imagem de satélite exibindo uma típica atuação da brisa terrestre, no início do semestre chuvoso, identificada por linhas de nuvens em forma de arco, sobre o oceano, e com origem nos litorais côncavos (anteriormente citados) entre o nordeste do Maranhão e o noroeste do Ceará, e entre Fortaleza e o norte do Rio Grande do Norte. No último caso, o extremo oeste da banda de nuvens se posicionou em torno de Fortaleza. Chuvas rápidas e leves foram, então, observadas na cidade e proximidades, incluindo Beberibe, Caucaia e Maranguape, em horários próximos ao da imagem de satélite. Outros exemplos bem típicos (não incluídos aqui), semelhantes ao apresentado foram observados para o período da estação chuvosa principal local tais como o do dia 16 de abril (próximo ao meio da estação) e de 24 de maio (no final da estação) de 2007, dentre outros.

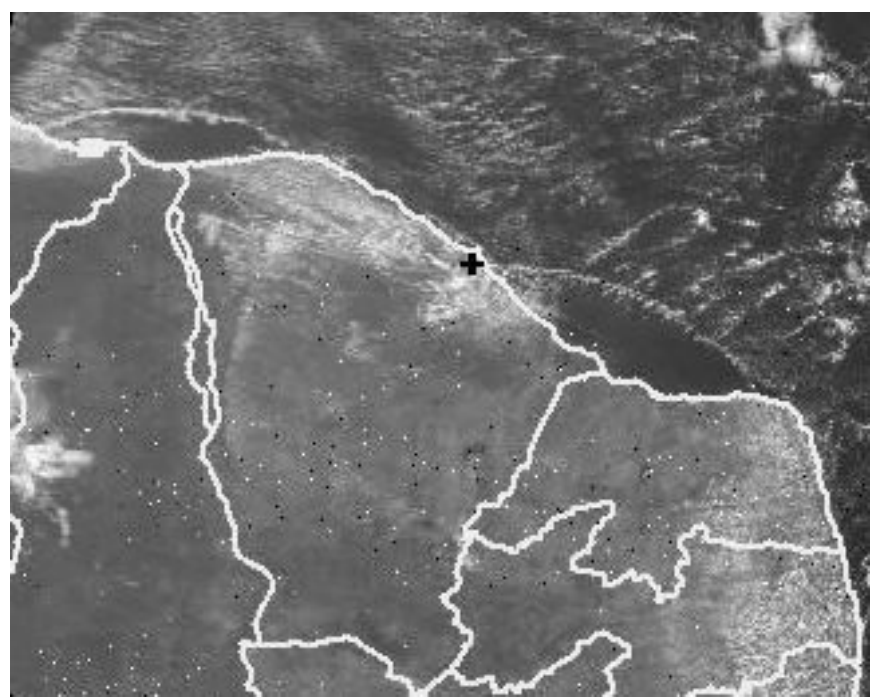

Figura 11 - Imagem, no visível, NOAA-14, 19/01/2007, 8:35 h local, mostrando linhas de nuvens associadas à brisas terrestres. Fortaleza aparece como uma pequena cruz.

No próximo exemplo (Figura 12) observa-se convergência de massa úmida e instável associada à ZCIT, com a brisa terrestre, desenvolvendo bastante a nebulosidade em parte da linha de nuvens em arco, associada à brisa, ocasionando chuva da ordem de $20 \mathrm{~mm}$ na área de Fortaleza. A chuva no litoral ao oeste da cidade pode ter sido facilitada pela brisa terrestre que ocorre entre o Maranhão e o Ceará.

É possível ainda, a brisa terrestre se acoplar a outros sistemas de grande escala, além da ZCIT, tais como as ondas de leste que algumas vezes alcançam o Ceará após o período da estação chuvosa principal local. A figura 13 mostra uma onda de leste chegando ao norte do Ceará. A brisa terrestre facilitou a ocorrência de chuva leve ( $4 \mathrm{~mm}$ ) devido a esse sistema na área de Fortaleza entre a madrugada e o início da manhã. Porém, 

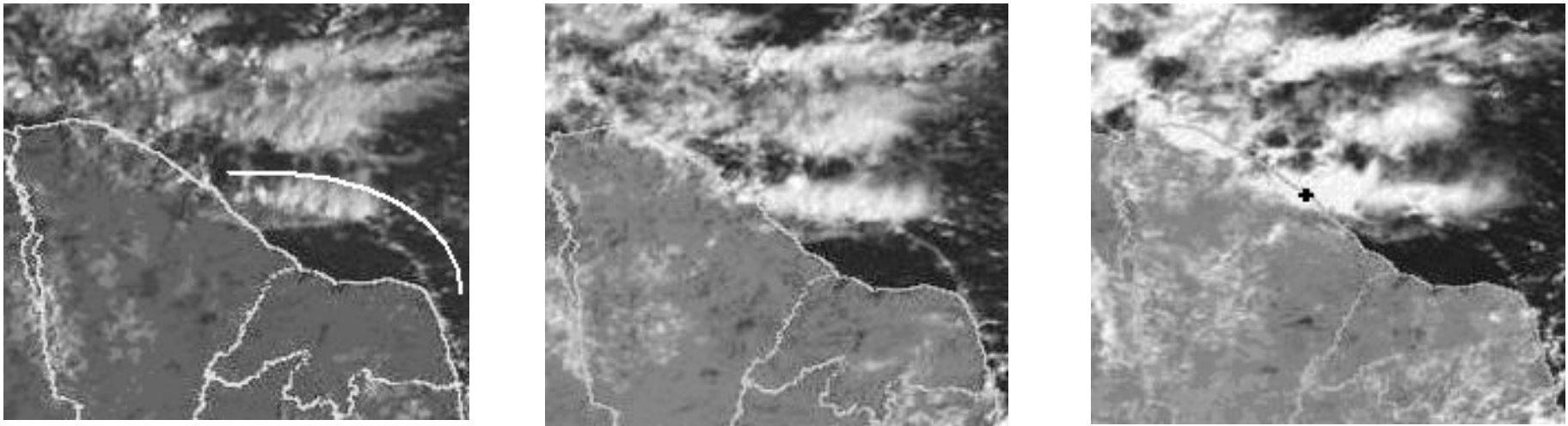

Figura 12 - Seqüência de imagens MSG-2 (no visível) mostrando acoplamento da brisa terrestre com a área de influência da ZCIT. Na primeira imagem (28/02/2007, 7:00 h local) foi desenhada uma linha branca para facilitar a identificação da linha de nuvens da brisa. A segunda imagem corresponde à mesma data, 8:00 h local, e a última imagem à mesma data, 9:00 $\mathrm{h}$ local. A pequena cruz preta indica Fortaleza.

a figura destaca a interação (convergência) da brisa terrestre formada a oeste de Fortaleza (com centro em $41^{\circ}$ Oeste, conforme citado anteriormente) com a onda de leste, facilitando a ocorrência de chuva em alguns municípios no litoral noroeste do Ceará, à oeste de Fortaleza. A imagem de satélite (retirada de uma seqüência de imagens) mostra nebulosidade associada à chuva no extremo oriental (sobre o Ceará) da linha de nuvens em forma de arco relacionada à brisa terrestre formada entre $o$ Maranhão e o Ceará.

\section{CONCLUSÃO}

A brisa terrestre (observável em imagens de satélite pela linha de nuvens, a ela associada, na forma de um grande arco em deslocamento para o oceano), em dependência, principalmente, da forma geométrica côncava do litoral entre Fortaleza e o norte do Rio Grande do Norte, da interação com os ventos sinóticos locais (os alísios de Sudeste geralmente quase paralelos à costa do norte do Nordeste) e da intensidade de sua própria circulação, parece favorecer, com a freqüente passagem de sua frente (o extremo ocidental do arco de nuvens) pela região de Fortaleza e vizinhanças, o aumento da freqüência de eventos de chuva entre a madrugada e o início da manhã na região, em qualquer época do ano. No entanto, considerando unicamente a atuação desse sistema, as chuvas tendem a ser rápidas e pouco intensas.

É possível ainda, que a brisa terrestre venha a interagir diversas vezes e em grau maior ou menor, com escoamento quase perpendicular à costa, do oceano para o continente (notadamente aquele associado à ZCIT, na estação chuvosa principal local), também contribuindo para aumentar a freqüência de chuva na referida região e no horário da madrugada para o início da manhã. Nestes casos, as chuvas tendem a ser mais intensas.

Além disso, pode também ocorrer o acoplamento da brisa terrestre com outros sistemas meteorológicos de grande escala
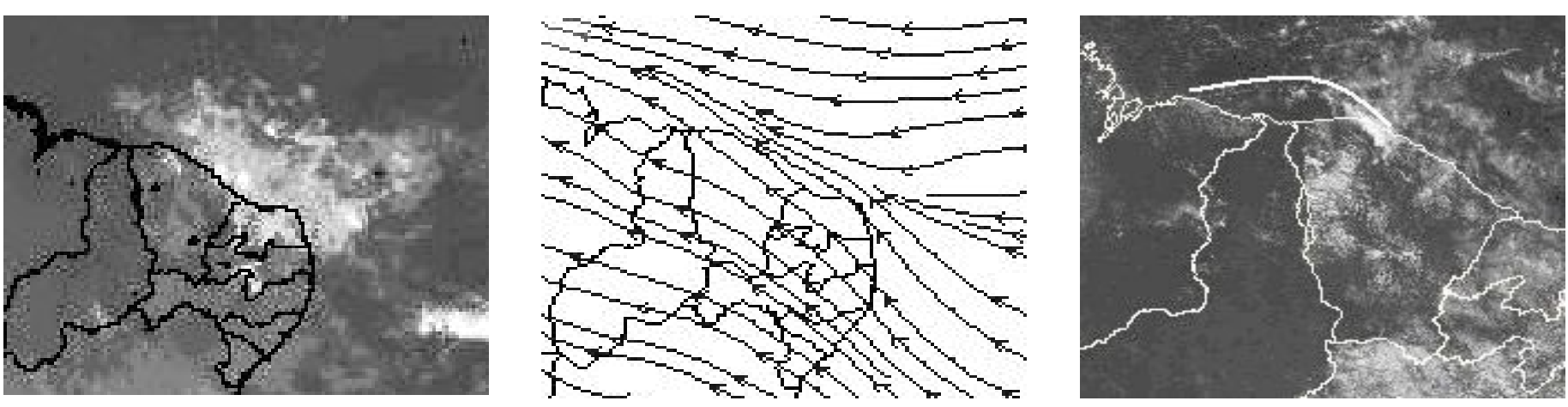

Figura 13: Onda de leste, 13/07/2007, 6:45 h local (à esquerda); linhas de corrente em $850 \mathrm{hPa}$ (análise, 12/07/2007, 21 h local) a partir de modelo regional (centro); brisa terrestre em interação com a onda de leste (uma linha branca foi desenhada acompanhando o arco de nuvens associado à brisa), 13/07/2007, 9:15 h local (à direita). Fonte: CPTEC/INPE. 
atuantes na região como, por exemplo, as ondas de leste que alcançam o Ceará após a estação chuvosa principal local.

De qualquer forma, a intensidade da circulação da brisa é fundamental no estabelecimento do grau de acoplamento (onde se espera que intensidade maior implique em acoplamento mais forte) com as massas de ar e os sistemas meteorológicos, porém, são sugeridos novos estudos para se verificar essa questão com maior detalhe.

Finalmente, a brisa terrestre tem sido menos estudada do que a brisa marítima porque ela tende a ser, em geral, menos intensa, menos comum e produzir chuva sobre o oceano e não sobre o continente (principalmente as áreas costeiras) onde se concentram os aglomerados urbanos e as atividades humanas. Mas, convém ressaltar, que no caso de Fortaleza, devido aos fatores mencionados, sua influência parece alcançar a cidade e seus arredores com certa importância, talvez tanto quanto em relação ao litoral leste do Nordeste.

Já a brisa marítima favorece a chuva mais para dentro da região litorânea do Ceará em detrimento da área costeira. É comum a observação de imagens de satélites mostrando a área de supressão de nuvens entre a região próxima à frente de brisa e a costa, no período da tarde. Isso ajuda a explicar a menor freqüência de chuva em Fortaleza, no período vespertino do dia. Se a cidade estivesse localizada não na orla marítima, mas um pouco mais para o interior do continente ela certamente receberia chuvas decorrentes de efeitos da brisa marítima.

\section{AGRADECIMENTOS}

O autor deseja agradecer aos dois revisores anônimos pelas valiosas sugestões que muito contribuíram para o aperfeiçoamento do presente trabalho.

\section{REFERÊNCIAS}

AHRENS, C. D. Essentials of meteorology: An invitation to the atmosphere.3.ed.Belmont:ThomsonBrooks/Cole, 2000.463p.

ATKINS, N. T.; WAKIMOTO, R. M.; WECKWERTH, T. M. Observations of the sea breeze front during CaPE. Part II: Dual-Doppler and aircraft analysis. Mon. Wea. Rev., Boston, v.123, p. $944-969.1995$.

BAKER, R. D. et al. The influence of soil moisture, coastline curvature, and land-breeze circulations on sea-breezeinitiated precipitation. J. of Hydrometeorology, Boston, v.2, p. 193 - 211. 2001.

DAILEY, P. S.; FOVELL, R. G. The sea-breeze and horizontal convective rolls. Mon. Wea. Rev., Boston, v. 127, p. 858. 1999. Disponível em: $<\mathrm{http}: / / w w w . a t m o s . u c l a . e d u / \sim$ fovell/ ASres/sbfhcr/sbfhcr.html\#Background $>$. Acesso em: novembro de 2006.
DECARIA, A. Exploring the land/sea breeze circulations. Lead to learn modules, Millersville. 2005. Disponível em: $<$ http://www.atmos.millersville.edu/ lead/modules.htm>. Acesso em: junho de 2007.

GILLE, S. T.; SMITH, S. G. L.; STATOM, N. M. Global observations of the land breeze. Geophys. Res. Lett., Washington, v. 32, L05605, 2005.

HASTENRATH, S.; HELLER, L. Dynamics of climate hazards in northeast Brazil. Quart. J. Roy. Meteor. Soc., Reading, v.103, p. $77-92.1977$.

HEIDORN, K. C. The weather doctor. Sea and land breezes. 1998. Disponível em: < http://www.islandnet.com/ see/ weather/elements/seabrz.htm>. Acesso em: junho de 2007.

KOUSKY, V. E. Diurnall rainfall variation in the Northeast Brazil. Mon. Wea. Rev., Boston, v.108, n.4, p. $488-498$. 1980.

KOUSKY, V. E. Frontal influences on northeast Brazil. Mon. Wea. Rev., Boston, v.107, p. 1140 - 1153. 1979.

McPHERSON, R. D. A numerical study of the effect of a coastal irregularity on the sea breeze. J. Appl. Meteor. ,Boston, v.9, p. $767-777.1970$.

PIELKE, R. A. A three dimensional numerical model of the sea breezes over south Florida. Mon. Wea. Rev., Boston, v.102, p. 115 - 139. 1974.

ROTUNNO, R. et al. Coastal Meteorology. A review of the state of the science. Panel on Coastal Meteorology, Committee on Meteorological Analysis, Prediction, and Research, Board on Atmospheric Sciences and Climate, Commission on Geosciences, Environment, and Resources, National Research Council, National Academy of Sciences. Washington: The National Academy Press, 1992. 112 p.

SIMPSON, J. E. Sea breeze and local wind. Cambridge: Cambridge Univ. Press, 1994. 234 p.

SIMPSON, N. E.; CLERMAN, R. J.; PIELKE, R. A. On cumulus mergers. Arch. Meteor. Geophys. Bioklimatol., Vienna, v.29, p. 1 - 40. 1980.

STRANG, D. M. G. Climatological analysis of rainfall normals in northeastern Brazil. Pap. No. IAE-M-02/72. Centro Técnico Aeroespacial. São José dos Campos, 1972. 70 p.

TEIXEIRA, R. F. B. Observação de linhas de convergência/ linhas de instabilidade e frentes de rajada, sobre o Ceará, utilizando imagens de satélites. In: XIII Congr. Bras. de Meteor., 2004, Fortaleza, Anais... CD-ROM, SMPTA7 -28, Fortaleza, 2004.

TEIXEIRA, R. F. B. A oscilação do Atlântico norte e a qualidade da quadra chuvosa do Ceará. In: XII Congr. Bras. de Meteor., 2002, Foz do Iguaçu, Anais... CD-ROM, CT1 - Climatologia Geral, Foz do Iguaçu, 2002.

VIANELLO, R. L.; ALVES, A. R. Meteorologia básica e 
aplicações, Viçosa: Imprensa Universitária, 1991. 449 p.

WAKIMOTO, R. M.; ATKINS, N. T. Observations of the seabreeze front during CaPE. Part I: Single-doppler, satellite and cloud photogrammetry analysis. Mon. Wea. Rev., Boston, v.122, p. 1092-1113. 1991.
WILSON, J. W. et al. Nowcasting thunderstorms: a status report. Bull. of the Am. Met. Soc., Boston, v.79, n.10, p. 2079 - 2099. 1998.

XAVIER, T. M. B. S. Tempo de Chuva. Estudos climáticos e de previsão para o Ceará e Nordeste setentrional. Fortaleza: ABC Editora, 2001. 478 p. 